\title{
Front Matter: Volume 11903
}

, "Front Matter: Volume 11903," Proc. SPIE 11903, Nanophotonics and Micro/ Nano Optics VII, 1190301 (18 November 2021); doi: 10.1117/12.2619354

SPIE. Event: SPIE/COS Photonics Asia, 2021, Nantong, Jiangsu, China 


\title{
PROCEEDINGS OF SPIE
}

Nanophotonics and

Micro/Nano Optics VII

\author{
Zhiping Zhou \\ Kazumi Wada \\ Limin Tong \\ Editors
}

\section{0-12 October 2021 \\ Nantong, China}

Sponsored by

SPIE

COS-Chinese Optical Society

Cooperating Organizations

Tsinghua University (China) - Peking University (China) - University of Science and Technology of China (China) • Zhejiang University (China) • Tianjin University (China) Beijing Institute of Technology (China) • Beijing University of Posts and Telecommunications (China) - Nankai University (China) - Changchun University of Science and Technology (China) - University of Shanghai for Science and Technology (China) • Capital Normal University (China) - Huazhong University of Science and Technology (China) • Beijing Jiaotong University (China) - China Jiliang University (China) - Shanghai Institute of Optics and Fine Mechanics, CAS (China) - Changchun Institute of Optics, Fine Mechanics and Physics, CAS (China) - Institute of Semiconductors, CAS (China) - Institute of Optics and Electronics, CAS (China) - Institute of Physics, CAS (China) Shanghai Institute of Technical Physics, CAS (China) • China Instrument and Control Society (China) The Optical Society of Japan (Japan) - Optical Society of Korea (Korea, Republic of) - Australia and New Zealand Optical Society (Australia) - Optics and Photonics Society of Singapore (Singapore) • European Optical Society

Supporting Organizations

China Association for Science and Technology (CAST) (China) - Department of Information of National Nature Science Foundation, China (NSFC) (China)

Published by

SPIE

Volume 11903 
The papers in this volume were part of the technical conference cited on the cover and title page. Papers were selected and subject to review by the editors and conference program committee. Some conference presentations may not be available for publication. Additional papers and presentation recordings may be available online in the SPIE Digital Library at SPIEDigitalLibrary.org.

The papers reflect the work and thoughts of the authors and are published herein as submitted. The publisher is not responsible for the validity of the information or for any outcomes resulting from reliance thereon.

Please use the following format to cite material from these proceedings:

Author(s), "Title of Paper," in Nanophotonics and Micro/Nano Optics VII, edited by Zhiping Zhou, Kazumi Wada, Limin Tong, Proc. of SPIE 11903, Seven-digit Article CID Number (DD/MM/YYYY); (DOI URL).

ISSN: 0277-786X

ISSN: 1996-756X (electronic)

ISBN: 9781510646551

ISBN: 9781510646568 (electronic)

Published by

SPIE

P.O. Box 10, Bellingham, Washington 98227-0010 USA

Telephone +1 3606763290 (Pacific Time)

SPIE.org

Copyright @ 2021 Society of Photo-Optical Instrumentation Engineers (SPIE).

Copying of material in this book for internal or personal use, or for the internal or personal use of specific clients, beyond the fair use provisions granted by the U.S. Copyright Law is authorized by SPIE subject to payment of fees. To obtain permission to use and share articles in this volume, visit Copyright Clearance Center at copyright.com. Other copying for republication, resale, advertising or promotion, or any form of systematic or multiple reproduction of any material in this book is prohibited except with permission in writing from the publisher.

Printed in the United States of America by Curran Associates, Inc., under license from SPIE.

Publication of record for individual papers is online in the SPIE Digital Library.

\section{SPIE. DIGITAL}

Paper Numbering: A unique citation identifier (CID) number is assigned to each article in the Proceedings of SPIE at the time of publication. Utilization of CIDs allows articles to be fully citable as soon as they are published online, and connects the same identifier to all online and print versions of the publication. SPIE uses a seven-digit CID article numbering system structured as follows:

- The first five digits correspond to the SPIE volume number.

- The last two digits indicate publication order within the volume using a Base 36 numbering system employing both numerals and letters. These two-number sets start with 00, 01, 02, 03, 04, 05, 06, 07, 08, 09, 0A, OB ... 0Z, followed by 10-1Z, 20-2Z, etc. The CID Number appears on each page of the manuscript. 


\section{Contents}

\section{D-FIBER/OD-NANOCRYSTALS}

1190303 Tapered MMF fiber/AuNPs/MoS 2 based sensor for $p$-cresol detection [1 1903-2]

1190304 Synthesis of copper halide nanocrystals and their optical properties [1 1903-3]

\section{RESONATOR/CAVITY}

1190305 Predicting the $Q$ factor and modal volume of photonic crystal nanocavities via deep learning [11903-4]

1190307 Slotted nanoresonator geometry: a route for Purcell enhancement and nearfield intensity amplification in all-dielectric nanophotonics [1 1903-6]

META/2D MATERIALS

1190308 Tuning resonant reflection in monolayer graphene nanosquare arrays at mid-infrared frequencies [11903-7]

11903 OB A numerical study of optical reconfiguration dynamics of phase change material metasurfaces [11903-10]

\section{SILICON PHOTONICS I}

11903 OF A beam scanner based on an on-chip optical switch array with high emission efficiency [11903-14]

$11903 \mathrm{OH}$ Dimensionality reduction in designing advanced silicon photonic components (Invited Paper) [11903-16]

\section{SILICON PHOTONICS II}

11903 0J Simultaneous detection of refractive index and temperature using high-order air and dielectric modes in a single photonic crystal nanobeam cavity [11903-19] 
11903 OW Vortex generation induced by the spin-orbit interactions in optics: a comparison [11903-29]

11903 OX Broadband high-efficiency reflective LTC polarization converter with temperature control in the visible range [1 1903-30]

11903 oY Tunable quad-band absorber based on graphene metamaterials [1 1903-31]

1190312 SiN-Si dual-layer grating coupler to increase the input optical power of Si-based photonicintegrated circuit [11903-35]

1190313 Research on nonlocal optical metasurfaces design based on the genetic algorithm method [11903-36]

1190314 A versatile metasurface for meta-nanoprinting and bifocal metalens [11903-37]

1190316 Computationally efficient algorithms to enhance multiple configuration systems [11903-39]

$1190317 \quad$ High Q-factor fano resonances driven by quasi bound state in the continuum based on alldielectric metasurface [1 1903-40]

$1190318 \quad$ Multiple plasmon-induced transparency effects derived by periodically arranged rectangular resonators in a plasmonic system [11903-41]

1190319 Influence of roughness on scattering characteristics of periodic micro-nano optical structures [1 1903-42]

$119031 \mathrm{C}$ Microstructure characterization and sidewall treatment of GaN/InGaN micro-light-emitting diodes [1 1903-45]

11903 IF Direct-growth and nonlinear properties of micron DAST hydrate waveguides [1 1903-48]

$1190311 \quad$ Design and analysis of bilayer metallic grating polarizer with tapered slits in deep ultraviolet band [11903-51]

$119031 \mathrm{~J} \quad$ High Q-factor fano resonances on permittivity-asymmetric dielectric meta-surfaces [1 1903-52]

11903 1K High Q-factor multiple fano resonances based on triple dielectric strips metasurface [1 1903-53] 